\title{
Withering's 1785 appeal for caution when reporting on a new medicine
}

\author{
Ulrich Tröhler
}

J R Soc Med 2007; 100:155-156

Additional material for this article is available from the James Lind Library website [www.jameslindlibrary.org], where this paper was previously published.

One lasting contribution to medicine since its discovery in the 18th century has been the beneficial effect of the leaves of foxglove (Digitalis purpurea) in 'dropsy', probably congestive heart failure in modern terms. The first systematic report of these effects-Account of the Foxglove and some of its Medical Uses with Practical Remarks on Dropsy and other Diseases — was authored by William Withering in 1785, and has become a classic. ${ }^{1}$ Much has been written about how an old country woman had directed Withering's attention to this plant, and on how he identified and specified the precise indications for it, and how it should be administered. ${ }^{2,3}$

The main reason for including the Preface of Withering's little book in the James Lind Library is that it warns against too hasty and potentially misleading publication of a few selected cases, either positive or negative. Withering also showed that he was aware of positive bias by the 'discoverers' of new medicines - what we would refer to today as reporting bias - and the means to minimize it. Single case reports were the most widespread way of publishing original observations in Withering's time, but although he had collected records of nineteen cases of 'dropsy' treated with digitalis before 1779, he decided not to report on the treatment until he had assembled all the 156 cases seen in his private practice, and seven whom he had treated at the Birmingham Hospital. As he wrote:

'It would have been an easy task to have given select cases, whose successful treatment would have spoken strongly in favour of the medicine, and perhaps been flattering to my own reputation. But Truth and Science would condemn the procedure. I have therefore mentioned every case . . . proper or improper, successful or otherwise.' (page vi).

One motive for Withering taking up the pen was that digitalis was being widely used as a panacea (in fact, he

Department of Social and Preventive Medicine (ISPM), University of Bern, Finkenhubelweg 11, CH-3012 Bern, Switzerland

Email: utroehler@ispm.unibe.ch closed his booklet with some deliberately tentative remarks on the use of digitalis in a variety of diseases other than dropsy). Withering's assembly of a large series of patients was probably one of the reasons that he succeeded in identifying the types of patients who would really benefit from digitalis; that is, patients suffering from oedema because of right heart failure, as we now know. His astuteness in this respect is all the more remarkable given that virtually nothing was known then about the pathophysiology of different kinds of oedema. In assessing the value of his treatment, Withering relied upon the clinical methods available to him-close observation of patients and attention to their subjective reports of their progress, assisted by counting the pulse and measuring urinary output. Withering thought a patient most likely to benefit ' . . . if the pulse be feeble or intermitting, the countenance pale, and the lips livid, the skin cold, the swollen belly soft and fluctuating, or the anasarcous [oedematous] limbs readily pitting under the pressure of the finger, [for then] we may expect the diuretic effects to follow in a kindly manner.' (pages 189-90). He compared these parameters with the patient's previous condition and sometimes observed relapses on discontinuing the drug.

In spite of the great care Withering had taken compared with other investigators, he urged his readers to be cautious in interpreting his findings, particularly as he felt that the patients he had treated were likely to have been more seriously ill, on average, than those seen by other physicians: 'No general deductions, decisive upon the failure or success of the medicine, can be drawn from the cases I now present . . . [for they] must be considered as the most hopeless and deplorable that exist . . . lost to the common run of practice and only snatched from destruction, by the efficacy of the Digitalis.' (pages vii-viii). In the main text of the book, he stressed the importance of respect for the criteria for arriving at a correct dose (namely, titration against the pulse). 'Three Hospital Cases which Dr Stokes at Stourbridge had an opportunity of observation are related as instances of bad practice, and tend to demonstrate how necessary it is when one physician adopts the medicine of another, that he should also at first rigidly adopt his method.' (page 151).

Withering limited his descriptions to his own cases because he was concerned that the cases [fellow physicians] have sent me are, with some exceptions, too much selected' by positive results and the readers of such an account would 
'. . close the book, with much higher notions of the efficacy of the plant than what they would have learnt from me.' (page ix). As he goes on to note in the Introduction, 'It is much easier to write upon disease than upon a remedy. The former is in the hands of nature, and a faithful observer, with an eye of tolerable judgment, cannot fail to delineate a likeness. The latter will ever be subject to the whims, the inaccuracies, and the blunders of mankind.' (page xix).

\section{REFERENCES}

1 Withering W. An Account of the Foxglove and Some of its Medical Uses: With Practical Remarks on Dropsy and Other Diseases. London: J and J Robinson, 1785

2 Aronson JK. An Account of the Foxglove and its Medical Uses 1785-1985. Oxford: Oxford University Press, 1985

3 Lee MR. William Withering (1741-1799): a biographical sketch of a Birmingham Lunatic. The James Lind Library (www.jameslindlibrary.org), 2005 